\title{
Pentatrichomonas hominis
}

National Cancer Institute

\section{Source}

National Cancer Institute. Pentatrichomonas hominis. NCI Thesaurus. Code C123541.

An obligate symbiont, flagellate protozoan in the family Trichomonadidae. P. hominis is found in the intestinal tract of infected individuals, but is considered nonpathogenic. 